\title{
Cost-effectiveness of a multi-professional case management experiment in Finnish labor market services
}

\author{
JAN KLAVUS ${ }^{1 *}$ \\ SAMI YLISTÖ ${ }^{2}$ \\ LEENA FORMA ${ }^{1}$ \\ JUSSI PARTANEN ${ }^{1}$ \\ PEKKA RISSANEN ${ }^{1,3}$ \\ MIKKO MÄNTYSAARI ${ }^{2}$ \\ ${ }^{1}$ Faculty of Social Sciences, Department of Health Sciences, University of Tampere \\ ${ }^{2}$ Faculty of Humanities and Social Sciences, University of Jyväskylä \\ ${ }^{3}$ National Institute for Health and Welfare, Helsinki
}

\begin{abstract}
The study undertook an economic evaluation of a multi-professional case management intervention targeted at long-term unemployed Finns. The cost-effectiveness outcome of the intervention was analyzed in a matched case-control study framework involving a six-month follow-up. Effectiveness was measured by standardized quality of life indicators, and an indicator measuring personal capabilities. Individual level costs were derived from health and social services utilization data. Cost-effectiveness of the intervention was examined in relation to services as usual. The studied labor market intervention was associated with a positive change in the selected quality of life indicators; physical and psychological quality of life improved in the intervention group. Costeffectiveness in physical quality of life was attained at a willingness to pay of EUR 500 700 per effectiveness unit, while cost-effectiveness in psychological quality of life required incremental costs exceeding EUR 1,600. The intervention had no discernible effect on personal capabilities. The study demonstrated that favorable improvements in quality of life could be attained by a rather 'light' and moderate-cost service concept. Such well-being improvements may enhance the preparedness for re-employment of individuals with a prolonged unemployment history. However, a longer follow-up of the labor market intervention would be needed to examine the long-term effects on quality of life and employment.
\end{abstract}

JEL classification: J08, H53, I14

Key words: long-term unemployment, labor policy, cost-effectiveness, welfare

* Correspondence to: Jan Klavus, Department of Health Sciences, Faculty of Social Sciences, University of Tampere, Finland. Email: jan.klavus@outlook.com.

Published: Online October 2020. dx.doi.org/10.5617/njhe.6863 


\section{Introduction}

Long-term unemployment imposes significant costs to the economy, society and individual. In an economic perspective, a high unemployment rate indicates that the economy is operating below its full capacity, which results in lower output and national income. Unemployment also engenders a reduction in tax revenue as less income and value-added taxes are being collected, while at the same time, the government is obliged to spend more on unemployment and related social security benefits. In the societal aspect prolonged alienation from the labor market may evoke social disorder and behavior patterns that produce negative externalities. Communities with a higher share of long-term unemployed workers tend to have higher rates of disorder, crime and violence (Nichols et al. 2013; Johnson et al. 2011). For the individual, long-term unemployment incurs a reduction in incomes, but also a loss of human capital through erosion of acquired skills and, particularly among younger individuals, skepticism about the value of investing in education and training (e.g. van Heeringen et al. 2001; Pissarides 1992; Möller 1989). There is robust scientific evidence that the unemployed are at greater risk of physical and mental illness, mortality and suicide, and that their overall well-being is lower than among their employed counterparts (Kim and Knesebeck 2015, 2016; Milner et al. 2013, 2014; Herbig et al. 2013; Roelfs et al. 2011; Paul and Moser 2009; Heponiemi et al. 2008; McKee-Ryan et al. 2005; Murphy and Athanasou 1999; Jin et al. 1995). In addition to contributing to unsatisfactory quality of life, impaired mental and physical health may deteriorate the long-term unemployed individual's capabilities for self-reliant job-seeking. In light of the high aggregate costs of unemployment, the opportunity costs of supportive labor market services for improving the unemployed individual's well-being, functional capabilities and prospects for employment may be of rather small magnitude. Such services include targeted health and social care, general guidance, personal job-oriented action plans, rehabilitative work experience, job search assistance and vocational training. These active labor market measures should be valued as social investments aiming at improving the prerequisites for employment, and be separated from active labor market measures that aim at enhanced work rotation and are being valued in terms of productivity costs or re-employment rates.

Finnish data show that relative to the general population, the long-term unemployed reported systematically lower scores on all four dimensions (physical, psychological, social, environment) of the WHOQOL-BREF quality of life indicator (Ylistö and Mäntysaari 2019). A previous Finnish study on the effects of active labor market measures on quality of life reported a significant relieve in mental anxiety among the study participants (Vuori et al. 2002). According to Vastamäki (2009), publicly subsidized programs involving job trials, in-job training or vocational education improved the participants' sense of coherence, control of life and sense of intelligibility. Further, among individuals engaged in a subsidized rehabilitative work activity trial, improvements in quality of life and sense of coherence had a reducing impact on psychiatric care costs (Pehkonen-Elmi et al. 2015). While the association of unemployment and poor health outcomes has been rather well documented, studies involving the costs and cost-effectiveness of employment related social interventions have been few both in Finland and internationally.

The present study undertook a cost-effectiveness analysis of a multi-professional case management (MCM) intervention targeted at long-term unemployed Finns. The data derived from a long-term unemployment survey conducted before and after the labor market intervention. The cost-effectiveness of the intervention was analyzed in a matched casecontrol framework involving a six-month follow-up. Effectiveness was evaluated by standardized quality of life indicators, and an indicator measuring personal capabilities, all included in the baseline and follow-up survey questionnaires. Individual level costs were 
dervied from the questionnaire's section on health and social services utilization. The costeffectiveness of the intervention was examined in relation to services as usual.

\section{Data and methods}

\subsection{Population}

The study population comprised of working-aged Finns who had been continuously unemployed for over 12 months prior to the study (long-term unemployed). At the national level, the long-term unemployment rate as percentage of the active population was $1.6 \%$ in 2018 (Eurostat 2020). The share of long-term unemployed of all unemployed in 2018 was $27.1 \%$ among males and $24.1 \%$ among females (Statistics Finland 2019).

\subsection{Intervention}

The intervention involved a multi-professional case management service (MCM) targeted at long-term unemployed individuals who had encountered difficulties in finding employment. The service was provided by labor force service centres (LAFOS) in five Finnish municipalities. There was slight variation in the implementation of the service concept between municipal provides, but generally they all compiled to the common MCMprotocol of LAFOS. The protocol is based on a principle that does not only focus on employment, but also takes into account the client's life situation in a more comprehensive manner (Karjalainen et al. 2008). New clients are enrolled by a referral procedure usually initiated by LAFOS and occasionally also by the social or the health care sector. The objective is to compose a tailored employment package matching the personal needs of the client. MCM starts by a comprehensive evaluation of the client's service needs, which are documented in a multi-professionally compiled employment plan. MCM may also include rehabilitative work experience, in-work experiment (work try-outs) and public health nurse services. The LAFOS basic services include rehabilitative, vocational, educational, social and health care services provided as outsourcing services or via case management. The unemployed are obliged to attend regular meetings provided by the LAFOS. These events offer information on employment possibilities and assistance in job-seeking techniques. The MCM-services should be distinguished from basic LAFOS-services, as they were available only to those unemployed enrolled for the program.

\subsection{Comparison}

The control group continued to use services as usual. These included health, social and employment services (other than MCM-services). A full description of items included in the service concept and the intervention is given in Appendix 1.

\subsection{Outcome: effectiveness}

The outcome indicators were chosen in relation to the aims and expected outcomes of the intervention. As for the impact on quality of life, the physical and psychological dimensions of the WHOQOL-BREF indicated highest responsiveness to the intervention, and they also indicated the closest intergroup match at the baseline. Beside the quality of life indicators, the outcome of the intervention was evaluated by the CAPABILITIES indicator. The capability approach emphasizes that wellbeing should not be measured according to what individuals actually do (functioning) but what they can do (capabilities) (Sen 1993; Nussbaum 2000). The approach was further elaborated by Anand et al. (2005) and Lorgelly et al. (2008) in form of developing a validated questionnaire for measuring the effect of 
social interventions on capabilities. A more detailed description of the outcome indicators and their scale is presented in Appendix 2.

\subsection{Study design}

The study population originated from two groups of long-term unemployed. The control group consisted of a sub-sample of individuals who had participated in a long-term unemployment survey (LTU) conducted in 2017 in five large to middle-sized Finnish municipalities (Helsinki, Kuopio, Joensuu, Jyväskylä and Lappeenranta). The final survey data consisted of 426 working-aged (21 -65) long-term unemployed individuals (for more details, see Klavus et al. 2018). Information on the duration of unemployment was merged from the register of Employment Services of Finland (URA-database). In order to form the control group, a random sample of 92 individuals was drawn from the LTU-survey database. The intervention group comprised of 92 non-randomized long-term unemployed who participated in a MCM intervention organized by LAFOS in 2017. A case-control study design was applied where the random sample of the long-term unemployment survey participants was pairwise matched with the MCM participants. The matching protocol used gender, age, education and WHOQOL-BREF quality of life dimensions as blocking variables (Fig. 1). The baseline data consisted of 184 individuals, while the final data only included cases where both the baseline and the follow-up questionnaires had been completed. Slightly higher attrition occurred in the control group and particularly among younger individuals. The final group sizes were 85 (intervention) and 77 (control).

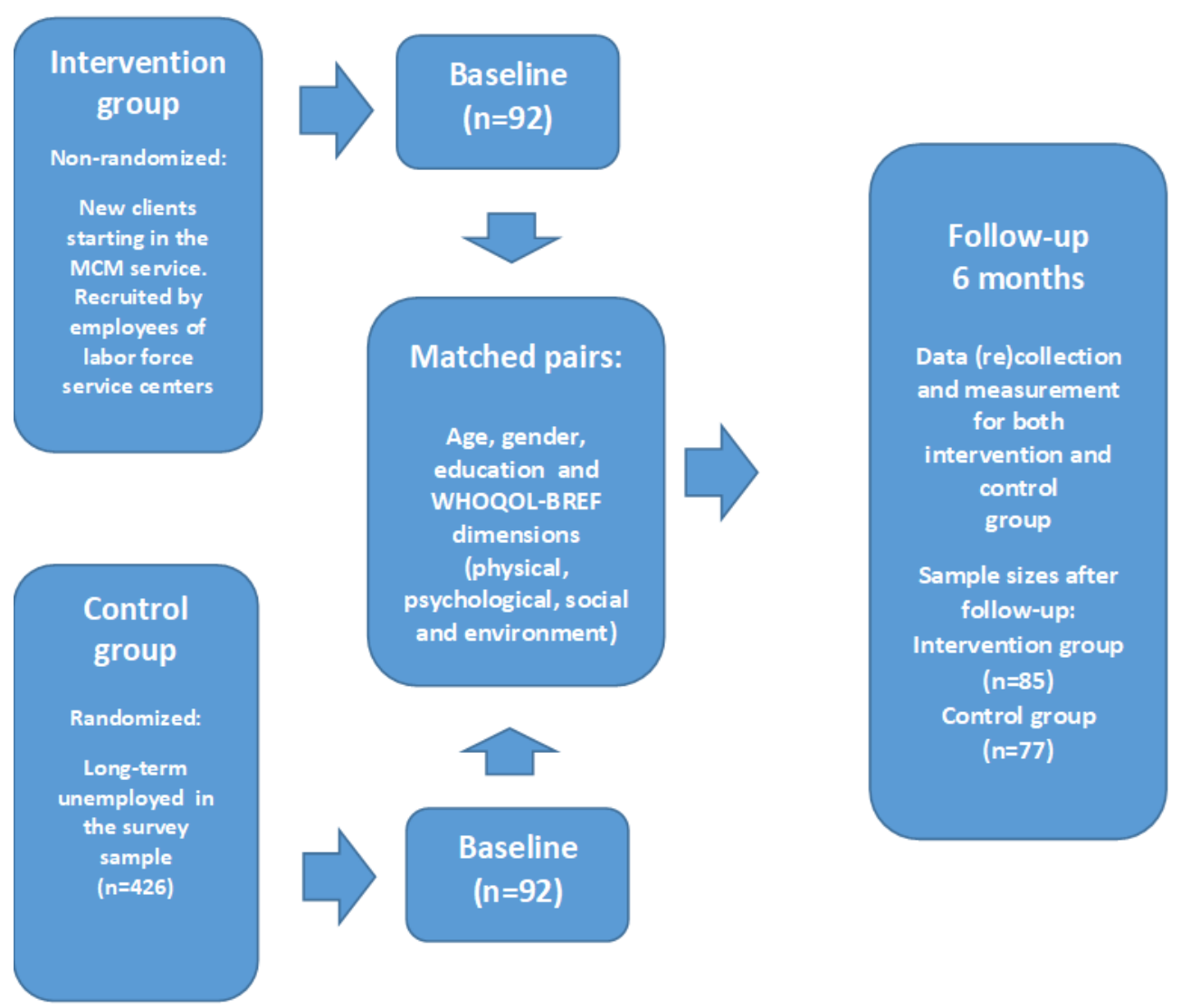

Figure 1: Study design 
Some variation existed in the group-specific distributions of gender, age, level of education, duration of unemployment and dimensions of social and environmental quality of life (Table 1). The average age was six years higher in the control group, which was largely due to the baseline age imbalance between the study groups (the control group had fewer individuals under 30 years of age). As for educational level, the control group had less individuals with only primary education and more individuals with an university degree. The percentage share of long-term unemployed with an unemployment spell over three years was higher in the control group. Apart from the age and duration of unemployment imbalance between the study groups, the differences in background characteristics showed no evidence of statistical significance. The quality of life scores were being matched within a ten-point acceptance level. Physical and psychological quality of life scores were closely matched, while a larger difference existed in social and environmental quality of life scores. However, the difference between study groups remained under the ten-point target level for all quality of life scores. In order to control for the differences in the background variables, the cost-effectiveness analysis was carried out by two estimation models: one using unadjusted data and another standardizing for age, gender education and duration of employment.

Table 1: Descriptive statistics at baseline ( $(\mathrm{sd}=$ standard deviation)

\begin{tabular}{|c|c|c|c|}
\hline & $\begin{array}{l}\text { Intervention } \\
\text { group } \\
\mathrm{n}=92\end{array}$ & $\begin{array}{l}\text { Control } \\
\text { group } \\
\mathrm{n}=92\end{array}$ & $\mathrm{p}$-value \\
\hline Age, mean (sd) & $45.0(10.1)$ & $50.7(9.6)$ & $0.000^{* * *}$ \\
\hline Gender (\%) & & & 1.000 \\
\hline Male & 44.6 & 44.6 & \\
\hline Female & 55.4 & 55.4 & \\
\hline Education (\%) & & & 0.415 \\
\hline Primary school or less & 25.0 & 19.6 & \\
\hline Vocational or high school & 69.6 & 70.7 & \\
\hline University degree & 5.4 & 9.8 & \\
\hline $\begin{array}{l}\text { Duration of unemployment } \\
\text { over } 3 \text { years }(\%)\end{array}$ & 46.3 & 63.5 & $0.032^{* *}$ \\
\hline \multicolumn{4}{|l|}{ WHOQOL-BREF, mean (sd) } \\
\hline Physical & $64.8(18.0)$ & $64.0(16.8)$ & 0.740 \\
\hline Psychological & $60.2(18.1)$ & $59.5(18.4)$ & 0.794 \\
\hline Social & $68.3(19.9)$ & $61.3(20.7)$ & $0.024^{* *}$ \\
\hline Environment & $65.6(12.9)$ & $60.9(15.3)$ & $0.029^{* *}$ \\
\hline
\end{tabular}


The reason for recruiting the study participants from two different lots of long-term unemployed was to ensure non-overlapping samples. The control group was composed of long-term unemployed in open unemployment (see for example Porket 1995), meaning that they were passive job-seekers not participating in active labor market measures during the follow-up. In effect, the control group did not participate in interventions that include work experience components such as rehabilitative work experience, in-work experiment or subsidized work. Advisory type LAFOS-services like career counselling and in-office courses might have been used by the control group. The MCM-intervention included multiprofessional counselling services, rehabilitative work experience and in-work experiment. As LAFOS health nurse services were to some extent also used by the control group, these were classified as non-MCM employment services. The adopted study design allowed distinguishing whether the unemployed in the MCM-service benefited from the intervention in comparison to those unemployed who did not participate in any of these services. Individuals whose status changed for pensioner or student during the intervention were excluded from the analysis. In addition, three individuals in the intervention group (none in the control) were employed during the follow-up period and were not included in the final data.

\subsection{Data collection}

Data collection involved two measurements and recall periods. At the baseline both study groups completed an identical long-term unemployment questionnaire encompassing a time period of the previous 12 months. Data collection was repeated using the same questionnaire after a six-month follow-up period. Consequently, the recall period varied from 12 months in the baseline to 6 months in the follow-up. In matching the pairs it was ensured that the time-span between responses of the intervention-control pairs did not exceed one month. The questionnaire covered respondents' background information, the WHOQOL-BREF and CAPABILITIES effectiveness indicators and sections on the use of health, social and employment services. The respondents were asked about the event and frequency of service use in the preceding 12 (baseline) and 6 (follow-up) months. National unit costs were applied in calculating the costs of health and social services utilization (Kapiainen et al. 2014). All unit costs were valued at 2017 prices using public services price indices (Statistics Finland 2018). The costs of the intervention comprised the costs of compiling an activation plan (at municipality and national employment services) and costs of included health and social services (mainly visits to a public nurse). In order to make the costs of the baseline and follow-up periods comparable, it was assumed that the use of services in the baseline period was distributed at the aggregate group level evenly throughout the 12 month period. The equivalent 6 month costs of the baseline period were calculated as: $\operatorname{COSTS}_{12 \text { months }} / 2=$ COSTS $_{6 \text { months. }}$ Only the 6 month follow-up period costs were used in cost-effectiveness analyses.

The costs of health and social services (including employment services) utilization differed by study group. The intervention group had higher costs of medical doctor and other outpatient care use as well as medicines both at baseline and follow-up (Table 2). An exception was inpatient care, where costs were higher in the control group. The difference in health and social services use may, to some extent at least, be explained by the enrollment process for the MCM-service. As some of the enrollment referrals originate from the health or social services sector, they often entail an existing services contact between the customer and a public health or social care provider. Altogether, the costs of health, social and employment services increased during the follow-up by EUR 131 in the intervention group and EUR 78 in the control group. The costs of the MCM-intervention equaled EUR 831. 
Table 2: Mean costs of health and social services utilization and the intervention (EUR)

\begin{tabular}{|c|c|c|c|c|}
\hline & \multicolumn{2}{|c|}{ Baseline -- 6 months ${ }^{1}$} & \multicolumn{2}{|c|}{ Follow-up -- 6 months } \\
\hline & $\begin{array}{l}\text { Intervention } \\
\text { group }\end{array}$ & $\begin{array}{l}\text { Control } \\
\text { group }\end{array}$ & $\begin{array}{l}\text { Intervention } \\
\text { group }\end{array}$ & $\begin{array}{l}\text { Control } \\
\text { group }\end{array}$ \\
\hline Health services & & & & \\
\hline Medical doctor & 102 & 57 & 118 & 72 \\
\hline $\begin{array}{l}\text { Other outpatient } \\
\text { care (incl. dentists) }\end{array}$ & 360 & 219 & 371 & 210 \\
\hline Inpatient care & 61 & 173 & 100 & 186 \\
\hline Medicines & 113 & 64 & 110 & 84 \\
\hline Social services & 65 & 20 & 89 & 27 \\
\hline $\begin{array}{l}\text { Employment } \\
\text { services }\end{array}$ & 38 & 13 & 82 & 45 \\
\hline $\begin{array}{l}\text { Total } \\
\text { Intervention }\end{array}$ & 739 & 546 & 870 & 624 \\
\hline$(\mathrm{MCM})$ & & & 831 & \\
\hline $\begin{array}{l}\text { Total (incl. } \\
\text { intervention) }\end{array}$ & & & 1701 & \\
\hline
\end{tabular}

${ }^{1}$ Calculated from 12 month costs

\subsection{Analysis}

The cost-effectiveness of the intervention was analyzed in relation to services as usual using the incremental cost-effectiveness ratio (ICER). The ICER point estimate, indicating between-group differences in costs and outcomes after the six month follow-up period, was calculated as follows:

$I C E R=(\Delta C 2-\Delta C 1) /(\Delta E 2-\Delta E 1)$, where

$\Delta \mathrm{C} 2=$ change in mean costs in the intervention group

$\Delta \mathrm{C} 1=$ change in mean costs in the control group

$\Delta \mathrm{E} 2=$ change in mean effectiveness score in the intervention group

$\Delta \mathrm{E} 1=$ change in mean effectiveness score in the control group

The statistical uncertainty related to the observed ICER point estimate was computed by means of non-parametric bootstrap simulation, where ICER was estimated from 5,000 re-samples of the original data (see for example, Davison and Hinkley 1997) The probability distribution of ICER was examined graphically by cost-effectiveness planes and costeffectiveness acceptability curves. The former indicates the percentage share of the estimated ICERs in each cost-effectiveness quadrant, while the latter depicts the likelihood of cost-effectiveness at different threshold values of the society's willingness to pay. The 
estimations were carried out for two separate bootstrap models. In the first model, the distinct group effect was estimated by linear regression of the group dummy on the timevariant change in the outcome indicator. The second model accounted for the effect of between-group variation in age, gender, educational level and duration of unemployment. A standardized bootstrap model was estimated by including dummy variables for group, age, gender, educational level and duration of unemployment (cut-off point at three years) in the estimated model.

\section{Results}

Physical and psychological quality of life (WHOQOL-BREF) improved in the intervention group, while an opposite development took place in the control group (Table 3). The intervention had no discernible effect on personal capabilities (CAPABILITIES). Incremental cost of EUR 1,052 gave rise to a 4.7 unit improvement in physical quality of life in the intervention group, which was equivalent to an ICER of EUR 226 per effectiveness unit. Psychological quality of life increased in the intervention group by 2.9 units relative to the control group. A one-unit increase in the psychological dimension corresponded to incremental costs of EUR 363.

In comparison to the outcome of the unadjusted model, the standardized model indicated higher effectiveness in physical and psychological quality of life (Table 3). The most distinct change took place in psychological quality of life, which increased from 2.9 to 3.8. Slightly higher effectiveness also applied to physical quality of life. Only the improvement in physical quality of life indicated strong statistical significance, but in the standardized model also the psychological dimension obtained significance under the ten percent level. An ambiguous effectiveness outcome applied to capabilities, where the incremental effectiveness of 1.1 was generated by a decrease in capabilities scores in both study groups, but less so in the intervention group. The standardization had a slight increasing impact on incremental costs. It should be noted that despite of accounting for the chosen set of observable background variables in the standardized model, the results may still include selection bias due to other omitted variables.

The results of the standardized model in form of cost-effectiveness planes and acceptability curves are illustrated in Figure 2. In the left-hand side figure, the black dot represents the observed cost-effectiveness point estimate and the gray dots the simulated estimates. The right-hand side figure depicts the cost-effectiveness acceptability curve. It graphs the probability and incremental costs of a one-unit improvement in effectiveness. As regards physical quality of life, about 99 percent of the ICER estimates were located in the upper-right quadrant of the plane, indicating higher effectiveness and higher costs (Fig. 2a). If the willingness to pay for the intervention was over EUR 500 per effectiveness unit, costseffectiveness in physical quality of life would be attained by 90 percent probability. In the range of EUR 700 willingness to pay, the probability of cost-effectiveness would increase to over 95 percent. A rather similar outcome obtained to psychological quality of life. About 95 percent of the estimates indicated higher effectiveness and higher costs in the intervention group (Fig. 2b). A willingness to pay of EUR 1,600 was required to achieve the 90 percent probability level for cost-effectiveness. As regards CAPABILITIES, the cost-acceptability curve levelled-off at about the 70 percent probability level and consequently costeffectiveness was not likely to be achieved. In comparison to the unadjusted model, the standardized model indicated a higher willingness to pay for cost-effectiveness in all the studied indicators (results available from the authors on request). 


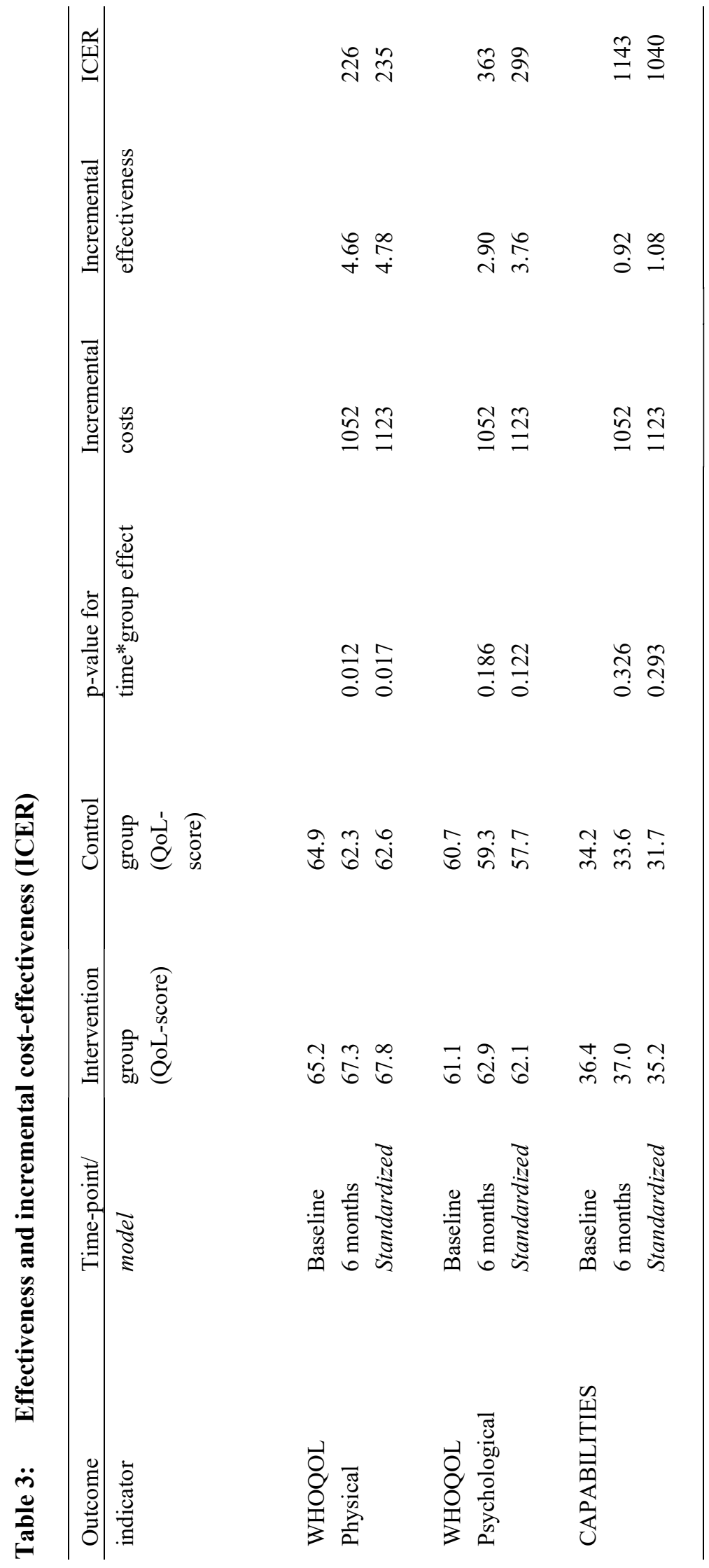


a) Physical dimension (WHOQOL-BREF)
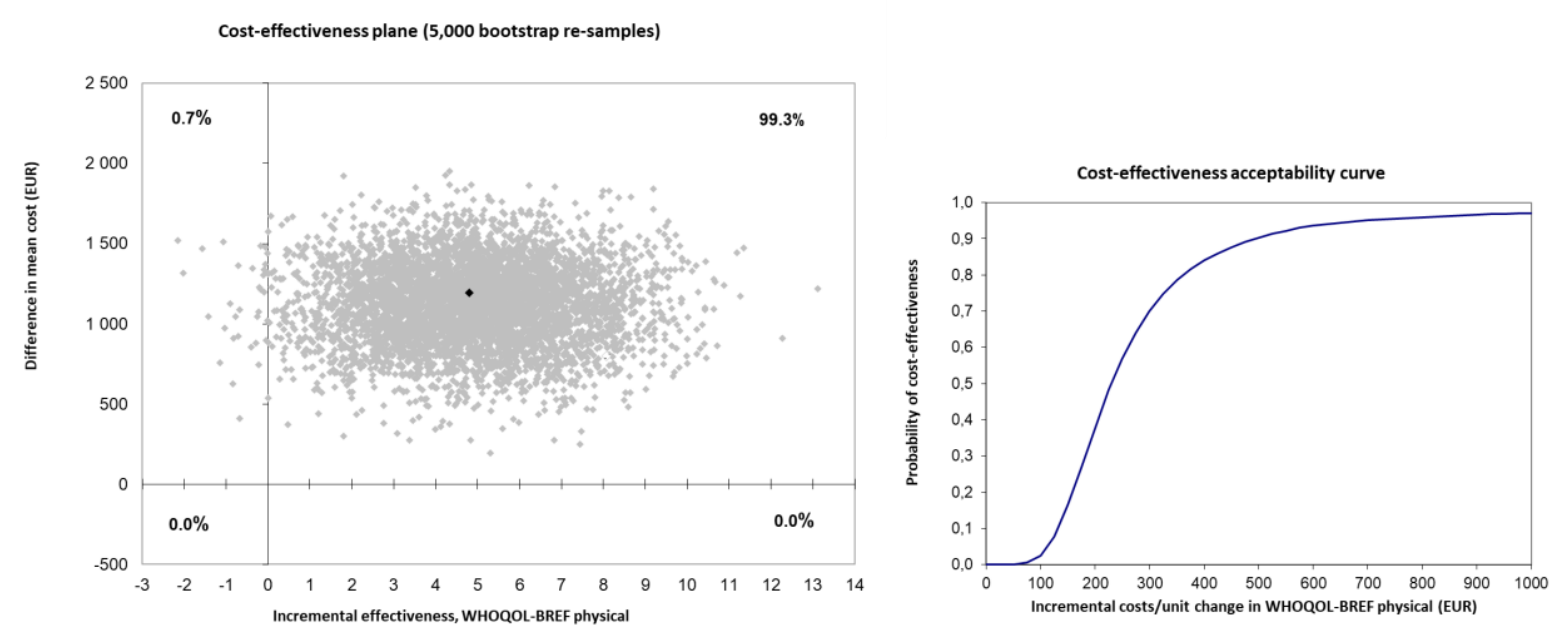

b) Psychological dimension (WHOQOL-BREF)
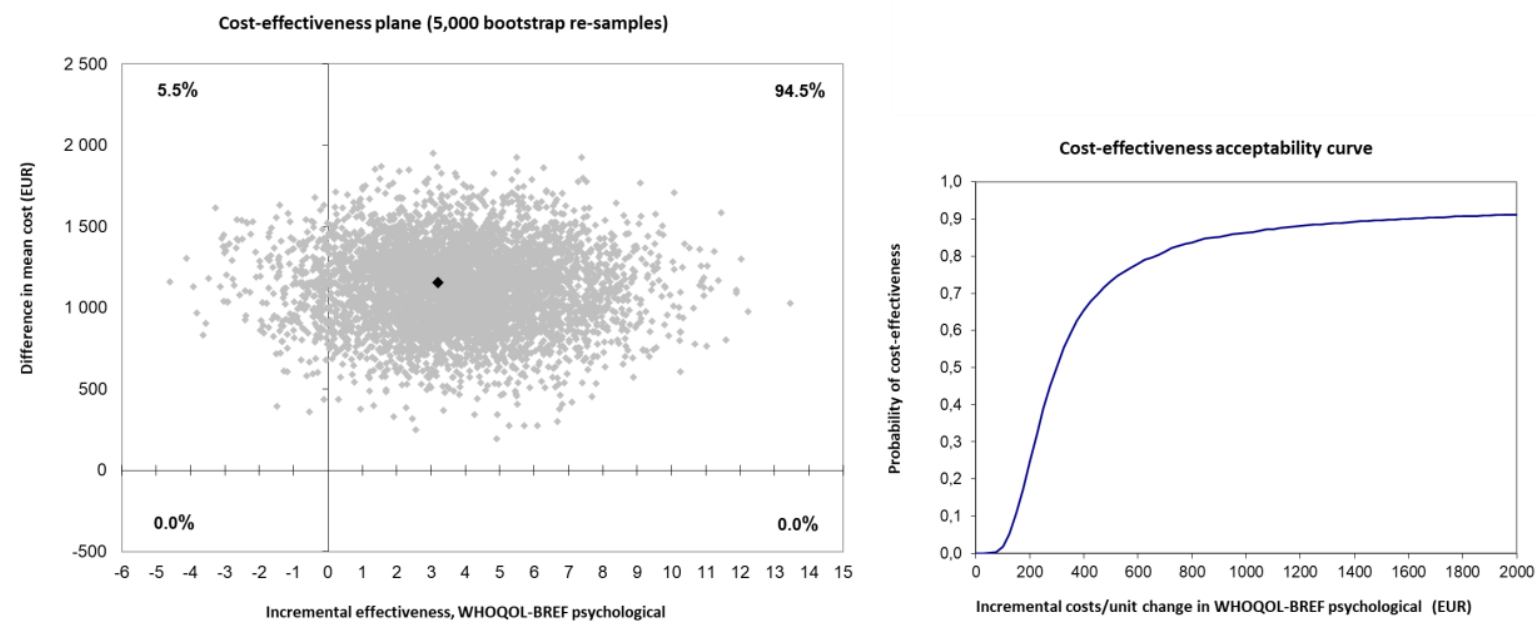

c) CAPABILITIES
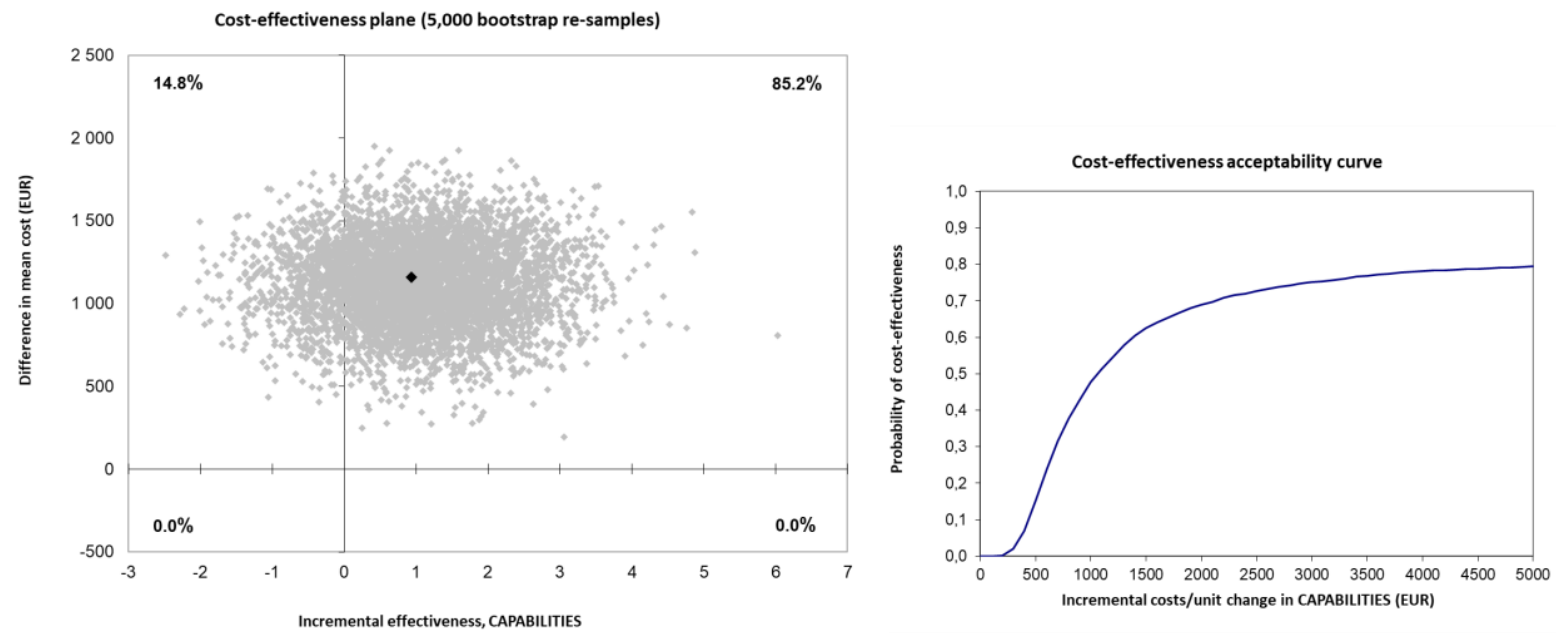

Figure 2: Cost-effectiveness planes and acceptability curves 


\section{Conclusions and discussion}

The studied labor market intervention (MCM) established a positive impact on two of the selected quality of life indicators. Physical and psychological quality of life improved in the intervention group, while in personal capabilities no meaningful effect was identified. Costeffectiveness in physical quality of life was attained at a willingness to pay of EUR $500-$ 700 per effectiveness unit, while cost-effectiveness in psychological quality of life required incremental costs exceeding EUR 1,600. The results indicated that the intervention displayed no evidence on attaining cost-effectiveness in personal capabilities.

The positive effects on long-term unemployed individuals' quality of life emerged in the context of a rather 'light' labor market intervention involving face-to-face counseling services of moderate production costs. While the MCM intervention did not guarantee employment, it seemed to induce a positive impact particularly on the individuals' physical, and to some extent also psychological, well-being.

Certain shortcomings of the study should be mentioned. First, as the study population originated from two different groups of long-term unemployed, some imbalance in the composition of the study groups existed. In order to account for systematic variation in age, gender, educational level and duration of unemployment, the analyzes were carried out both on unadjusted and standardized data. While the standardization accounted for differences in some of the background variables, the results may still include estimation bias due to other omitted variables. Secondly, the content of the MCM intervention was tailor-made to match the needs of the client, and therefore, certain variation in the implementation and costs at the individual level may have existed. However, as the MCM services follow largely a common protocol, the variation in the content and costs of the intervention was likely to be rather marginal. Lastly, the follow-up period of six months was relatively short for evaluating the full impact of the intervention. While the eventual outcome on long-term unemployed individuals' quality of life will depend on factors such as prospects for reemployment, continuity of the service and personal characteristics, the intervention seemed to contribute positively to the quality of life related well-being of the long-term unemployed.

With these limitations in mind, the findings were supportive in favor of active labor market measures aiming at enhancing the well-being of individuals with prolonged isolation from work-life. The scientific framework of the study aimed at complementing previous Finnish research on the subject, which has mainly focused on the effectiveness outcomes of employment related social interventions. The principal policy message of the study was that improvements in the well-being of vulnerable population groups, such as the long-tern unemployed, may be achieved by well-planned and correctly targeted social services interventions. The implementation of such interventions would benefit from an economic evaluation of the outcomes in order to inform decision makers on the costs and potential benefits of existing or planned social services programs.

\section{Acknowledgements}

We would like to thank two anonymous referees for their constructive comments on earlier drafts of this paper. We are also grateful to Jani Raitanen from the University of Tampere for his invaluable assistance on technical matters. 


\section{References}

Anand, P., Hunter, G. and Smith R. (2005). Capabilities and well-being: evidence based on the SenNussbaum approach to welfare. Social Indicators Research, 74, 9-55.

Davison, AC. and Hinkley, DV. (1997). Bootstrap methods and their application. Cambridge: Cambridge University Press.

Eurostat (2020). https://ec.europa.eu/eurostat/tgm/refreshTableAction.do;jsessionid=iyZI7Mq OPLbRIKztKQ7Hjv9dvgzvX66NG6BaJmtplqUjQw5CWYEW!1619364693?tab=table\&plug in $=1 \&$ pcode $=$ tipslm $70 \&$ language $=$ en

van Heeringen, K., La Rosa, M., Lemkow, L., Sokou, K. and Starrin, B. (2001). Living on the edge - an empirical analysis on long-term youth unemployment and social exclusion in Europe. Springer Fachmedien, Wiesbaden GmbH.

Herbig, B., Dragano, N. and Angerer, P. (2013). Health in the long-term unem-ployed. Deutsches Ärzteblatt International, 110, 413-9.

Heponiemi, T., Wahlström, M., Elovainio, M., Sinervo, T., Aalto, AM. and Keskimäki. (2008). A review of the associations between unemployment and health. Ministry of Economic Affairs and Employment of Finland. Publications; 14.

Hoffmann, K., Schori, D. and Abel, T. (2013). Self-reported capabilities among young male adults in Switzerland: Translation and psychometric evaluation of a German, French and Italian version of a closed survey instrument. Social Indicators Research, 114, 723-738.

Jin, RL., Shah, CP. and Svoboda, TJ. (1995). The impact of unemployment on health: a review of the evidence. CMAJ 153, 529-40.

Johnson, R., Rucker, C. and Schoeni. RF. (2011). The Influence of Early-Life Events on Human Capital, Health Status, and Labor Market Outcomes over the Life Course. B.E. Journal of Economic Analysis \& Policy: Advances, 11(3).

Kapiainen, S., Väisänen, A. and Haula T. (2014). Unit costs of health and social services in Finland 2011. National Institute for Health and Welfare 2014:3.

Karjalainen, K., Saikku, P., Pasuri, A. and Seppälä, A. (2008). Mitä on aktiivinen sosiaalipolitiikka kunnassa? Näköalapaikkana työvoiman palvelukeskus. Helsinki: Stakes.

Kim, TJ. and von dem Knesebeck, O. (2016). Perceived job insecurity, unem-ployment and depressive symptoms: A systematic review and meta-analysis of prospective observational studies. Int. Arch. Occup. Environ. Health. 89, 561-573. https://doi.org/10.1007/s00420-015$1107-1$.

Kim, TJ. and von dem Knesebeck, O. (2015). Is an insecure job better for health than having no job at all? A systematic review of studies investigating the health-related risks of both job insecurity and unemployment. BMC Public Health, 15, 985. https://doi.org/10.1186/s12889-015-2313-1.

Klavus, J., Forma, L., Partanen, J. and Rissanen, P. (2018). Need and utilization of primary health care among long-term unemployed Finns. Journal of Health and Social Sciences 2018(3), 231242.

Lorgelly, P.K., Lorimer, K., Fenwick, E and Briggs, A.H. (2008). The Capability Approach: developing an instrument for evaluating public health interventions: Final Report. University of Glasgow, Section of Public Health and Health Policy.

McKee-Ryan, F., Song, Z., Wanberg, C.R. and Kinicki, A.J. (2005). Psychological and Physical Well-Being During Unemployment: A Meta-Analytic Study. Journal of Applied Psychology, 90, 53-76.

Milner, A., Page, A. and LaMontagne, AD. (2014). Cause and effect in studies on unemployment, mental health and suicide: a meta-analytic and conceptual review. Psychol. Med. 44, 909-917. https://doi.org/10.1017/S0033291713001621. 
Milner, A., Page, A. and LaMontagne, AD. (2013). Long-Term Unemployment and Suicide: A Systematic Review and Meta-Analysis. PLoS One 8, e51333. https://doi.org/10.1371/journal.pone.0051333.

Murphy, GC. and Athanasou JC. (1999). The effect of unemployment on mental health. J. Occup. Organ. Psychol. 72, 83-99.

Möller, J. (1989). Unemployment and deterioration of human capital: A labour market model with hysteresis implications. Diskussionsbeiträge: Serie 1, Fakultät für Wirtschaftswissenschaften und Statistik, Universität Konstanz, No. 245,

Nichols, A., Mitchell, J. and Lindner, S. (2013). Consequences of long-term unem-ployment. The Urban Institute Reports, 2013. Washington D.C.

Nussbaum, M. (2000). Women and human development: The capabilities aproach. New York: Cambridge University Press.

Paul, K.I. and Moser, K. (2009). Unemployment impairs mental health: Meta-analyses. Journal of Vocational. Behaviour, 74, 264-282.

Pehkonen-Elmi, T., Kettunen, A., Surakka, A. and Piirainen, K. (2015). Vaikeasti työllistyville suunnattujen aktivointitoimenpiteiden taloudellinen analyysi - esimerkkeinä korkein korotettu palkkatuki ja kuntouttava työtoiminta (in Finnish). Diakonia ammattikorkeakoulun julkaisuja A Tutkimuksia 42 [A Studies 42]. Juvenes Print Oy, Tampere 2015.

Pissarides, CA. (1992). Loss of Skill During Unemployment and the Persistence of Employment Shocks. The Quarterly Journal of Economics 107 (4) 1371-1391.

Porket, JL. (1995). Causes of Open Unemployment. In: Unemployment in Capitalist, Communist and Post-Communist Economies. St Antony's/Macmillan Series. Palgrave Macmillan, London.

Roelfs, D.J., Shor, E., Davidson, K.W. and Schwartz, J.E. (2011). Losing life and livelihood: A systematic review and meta-analysis of unemployment and allcause mortality. Social Science and Medicine, 72, 840-854.

Sen, A. (1993). Capability and Well-being. In M. Nussbaum and A. Sen (Eds.), The Quality of Life. Oxford: Clarendon Press.

Statistics Finland (2018). Price index of public expenditure [e-publication]. Helsinki: Statistics Finland [referred: 26.8.2018]. Access method: http://www.stat.fi/til/jmhi/index_en.html

Statistics Finland (2019). Employment [e-publication]. ISSN=2323-6825. Background Information On Unemployed Persons 2018. Helsinki: Statistics Finland [referred: 26.8.2019]. Access method:http://www.stat.fi/til/tyokay/2018/02/tyokay_2018_02_2019-05-24_tie_001_en.html.

Vastamäki, J. (2009). Sense of coherence and unemployment. Academic dissertation. University of Erlanger-Nuremberg and University of Kuopio. http:// wanda.uef.fi/ukuvaitokset/vaitokset/2009/isbn000-000-00-0000-0.pdf.

Vuori, J., Silvonen, J., Vinokur, AD. and Price, RH. (2002). The job search program in Finland: benefits for the unemployed with risk of depression or discouragement. Journal of Occupational Health Psychology, 7, 5-19.

World Health Organization (1996). WHOQOL-BREF: Introduction, administrtion, scoring and generic version of the assessment. WHO, Geneva.

Ylistö, S. and Mäntysaari, M. (2019) Social quality of the Finnish long-term un-employed. Report of baseline data analysis. Manuscript in review.

(C) 2020 by the author(s). This article is an open access article distributed under the terms and conditions of the Creative Commons Attribution license (http://creativecommons.org/licenses/by/4.0/). 


\title{
Appendix 1
}

\section{Service items included in the "services as usual" concept and the intervention}

\author{
Medical doctor \\ Primary care \\ Secondary care \\ Private care \\ Dentist
}

Other consultations

Nurse/ public health nurse

Dental technician

Social worker

Psychologist

Services counsellor (Kela)

Hospital services

Primary care hospital

Secondary care hospital

Medicines

Prescription

Over the counter

Employment services

LAFOS-meeting (obligatory)

LAFOS-tutorial

course

Career/ vocational guidance

Career and work-related training

Health examination (for unemployed)

MCM-intervention

MCM-meeting with a multi-professional team

Rehabilitative work experience

In-work experiment 


\section{Appendix 2}

\section{Effectiveness indicators}

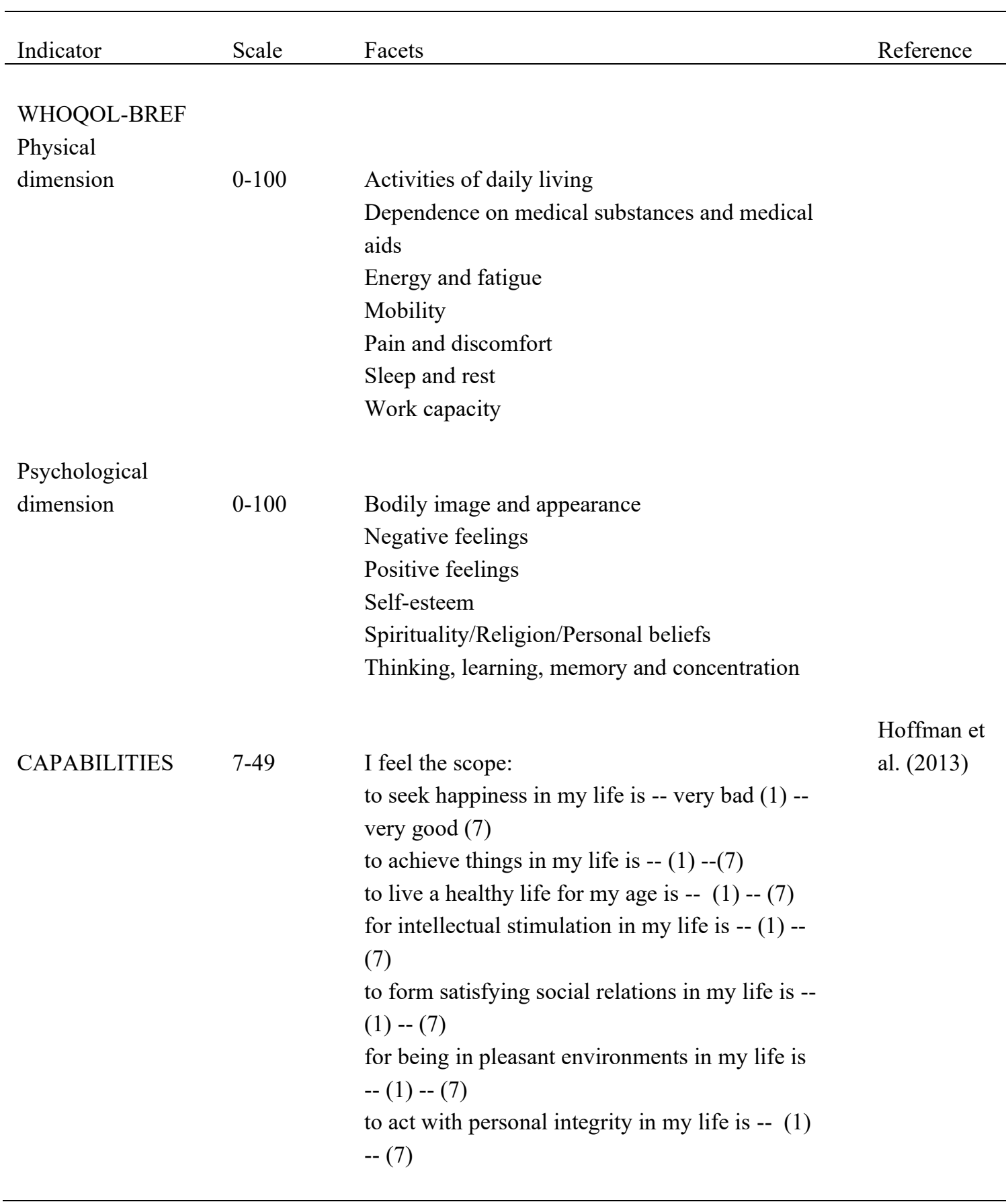

